\title{
Measuring Muscle Mass and Strength in Obesity: a Review of Various Methods
}

\author{
Dionne Sizoo ${ }^{1,2}$ (I) - Loek J. M. de Heide ${ }^{2}$. Marloes Emous ${ }^{2} \cdot$ Tim van Zutphen ${ }^{1} \cdot$ Gerjan Navis $^{3}$ • André P. van Beek ${ }^{2,4}$
}

Received: 26 March 2020 / Revised: 14 October 2020 / Accepted: 21 October 2020 / Published online: 6 November 2020

(C) The Author(s) 2020

\begin{abstract}
Lower muscle mass in populations with obesity is associated obesity-related diseases like hypertension and type 2 diabetes mellitus. Bariatric surgery leads to sustained weight loss. During the weight reduction, loss of muscle should be minimized. Thus reliable quantification of muscle mass is much needed and therefore the also the need for validated methods. Imaging methods, magnetic resonance imaging and computed tomography scan, have been the gold standard for many years. However, these methods are costly and have limitations such as the maximum weight. Dual-energy X-ray absorptiometry is currently the most used alternative. Other, less expensive methods are very limited in their validation in populations with morbid obesity. This narrative review summarizes the current knowledge regarding measuring muscle mass and strength in obesity.
\end{abstract}

Keywords Obesity $\cdot$ Muscle mass $\cdot$ Methods $\cdot$ Body composition

\author{
Abbreviations \\ ADP Air displacement plethysmography \\ BIA Bioelectrical impedance analysis \\ BMI Body mass index \\ CT Computed tomography \\ DXA Dual-energy X-ray absorptiometry \\ FFM Fat-free mass \\ FM Fat mass \\ L3 Third lumbar \\ MF Multi-frequency \\ MRI Magnetic resonance imaging \\ SFT Skinfold thickness
}

Dionne Sizoo

D.sizoo@rug.nl

1 Department of Health and Food, Campus Fryslân, University of Groningen, Leeuwarden, the Netherlands

2 Center Obesity Northern Netherlands (CON), Department of Surgery, Medical Center Leeuwarden, Leeuwarden, the Netherlands

3 Department of Internal Medicine, Division of Nephrolog, University Medical Center Groningen, University of Groningen, Groningen, the Netherlands

4 Department of Endocrinology, University Medical Center Groningen, University of Groningen, Groningen, the Netherlands
TD2 Type 2 diabetes mellitus

US Ultrasonography

\section{Background/Introduction}

Bariatric surgery is able to achieve sustained significant weight loss providing major health benefits $[1,2]$. The focus of bariatric surgery is on reduction of fat mass (FM), as FM is an important determinant of co-morbidity, e.g., type 2 diabetes (TD2) and hypertension [3, 4]. However, muscle mass is equally important. The health risks of low muscle mass have been well documented in populations of older adults $[5,6]$ but awareness of low muscle mass and its health risks in obesity are lagging behind. In obesity, low muscle mass and function are associated with lower psychological health, quality of life and increased all-cause mortality [7, 8]. Furthermore, TD2 and hypertension are more common with lower muscle mass [9]. Accordingly, preservation of muscle mass during weight loss after bariatric surgery is clinically relevant. A recent study showed that after gastric sleeve surgery patients lost an average $10 \%$ lean body mass in the first month and $17 \%$ loss after 1 year $[10,11]$. In preparing for surgery, patients on a very-low caloric diet lost more lean mass than FM [12]. These data underscore the need to decrease the loss of muscle mass both before and after the surgery. This implicates the need for validated methods to estimate muscle mass, which have already been 
established in healthy and elderly populations [13-15]. Validated methods for measuring muscle strength in populations with obesity might also be helpful, as muscle strength is positively related to muscle mass [16] and quality of life [17, 18]. In this paper, we review the methods of quantifying muscle mass and muscle strength, and their validation in populations with obesity.

\section{Methods}

In July 2019, the review started with a systematic literature search on validating methods to measure muscle mass in populations with obesity (Fig. 1). The search was performed in Pubmed, Embase, and Web of Science. Search terms used were: "muscle*, lean mass, lean body mass, fat free body weight, muscular mass or lean body weight" and "obesit*, obese or adipos* and ("dual energy x ray absorptiometry, dexa, dxa, densiometr*" or "MRI, magnetic resonance imaging" or computed tomography, CT, tomography"). Selection was performed independently by two reviewers and consensus was obtained on the results. Of the 6267 articles found, 6117 were excluded based on title and abstract. After assessing the full test of the remaining 50 articles, 11 articles remained (Table 1). The articles finally selected contained mostly small numbers of subjects, usually less than 100 , were very heterogeneous in characteristics of the population, gold standards and methods of measurement. We therefore concluded that a narrative review would be more appropriate for this topic. Articles found with the systematic search are included in the narrative review.

\section{Results}

The results are divided into three topics: definitions of muscle mass, methods to measure muscle mass and measurement of muscle strength.

\section{Definitions of Muscle Mass}

Many different terms are used in studies about muscle mass, e.g., lean mass or lean tissue mass, fat-free mass (FFM) and muscle mass. The muscle mass contains the weight of the muscles, including skeletal and smooth muscles. The term appendicular skeletal muscle mass only includes the skeletal muscles from the limbs [30]. The term lean tissue mass and FFM are not interchangeable. The lean tissue mass is the FFM together with

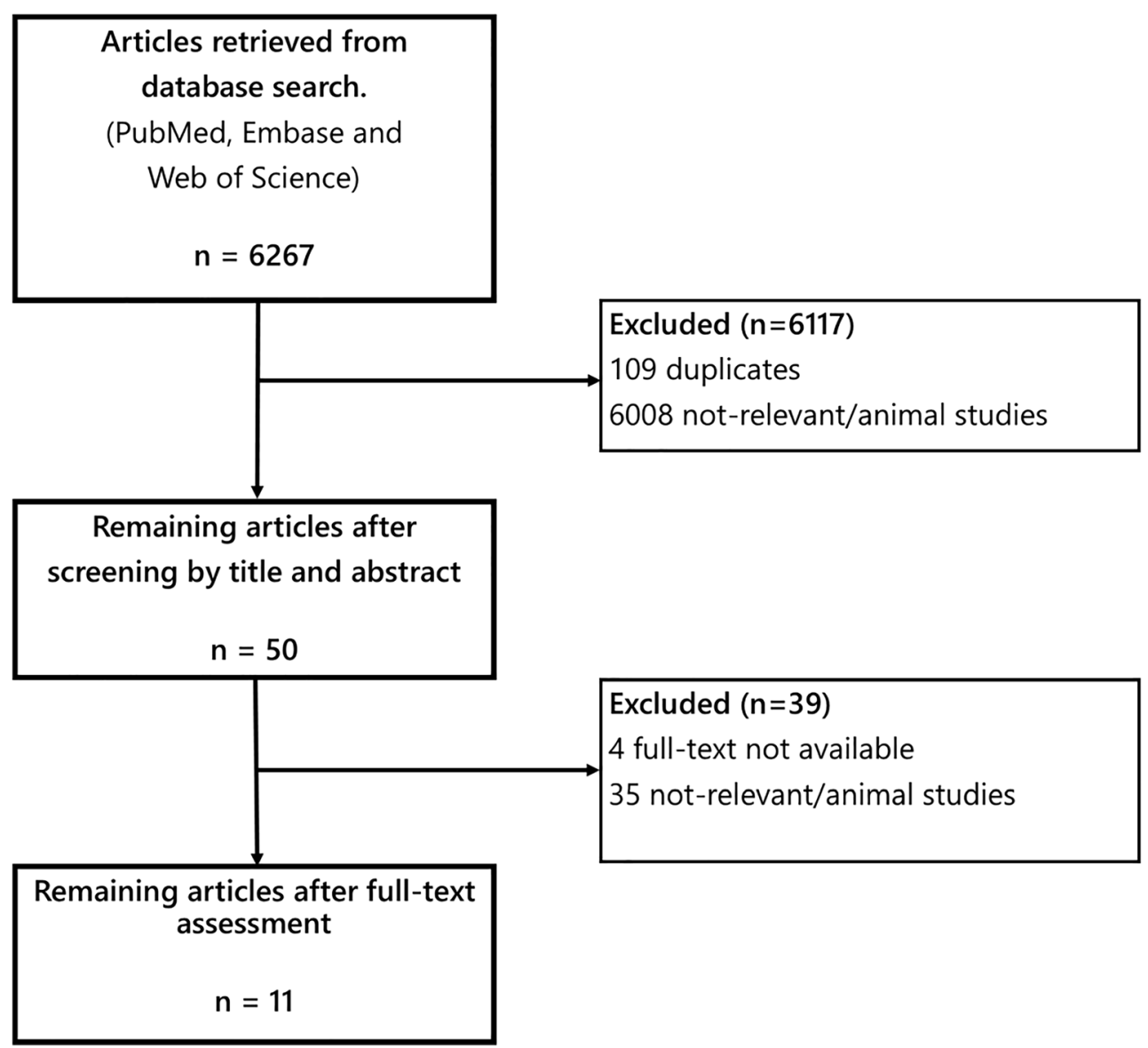

Fig. 1 Flow-chart of systematic search 


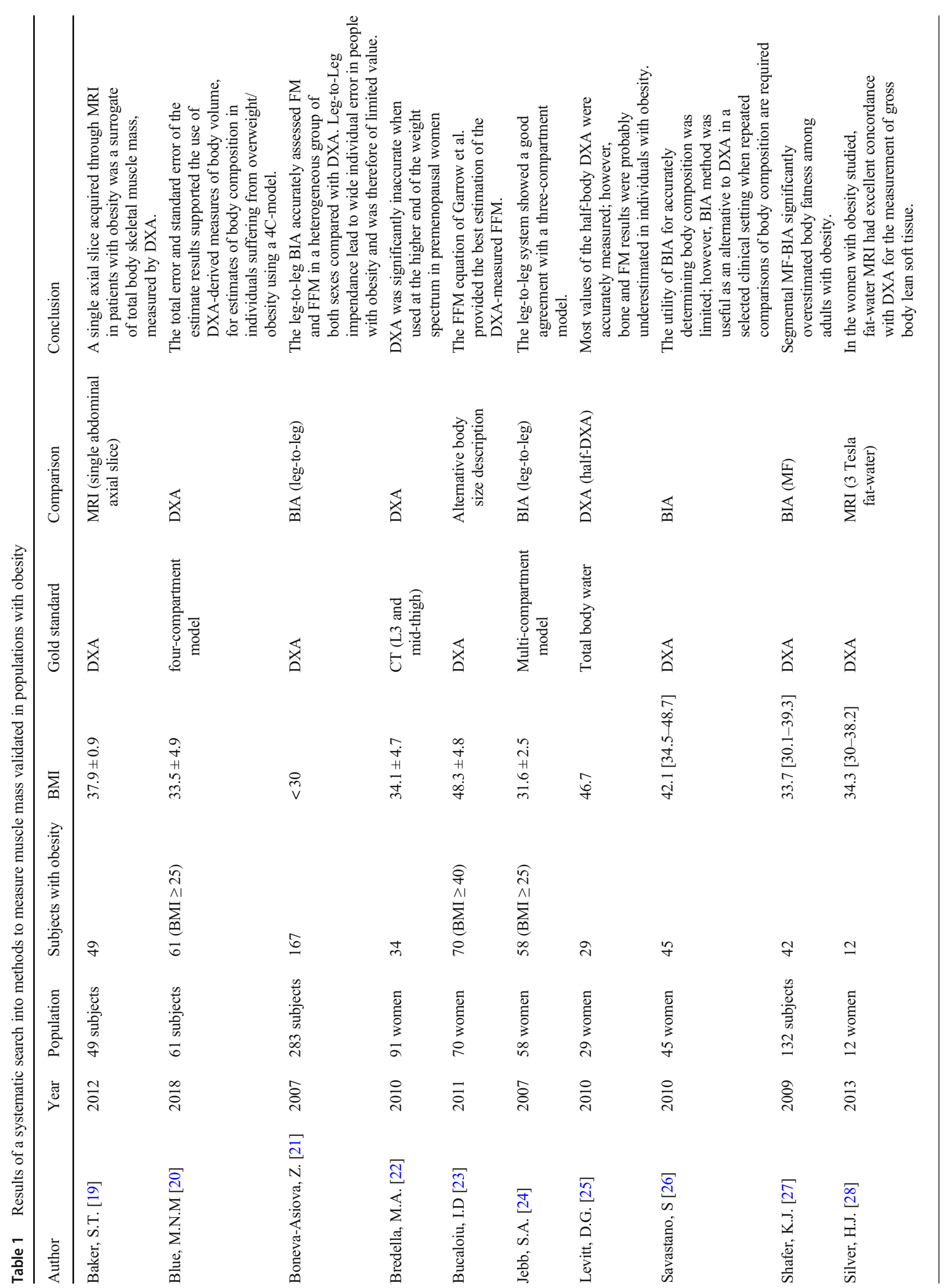


essential fat (e.g., in bone marrow or in organs). This amount of essential fat is in non-obese individuals approximately $2-17 \%$ of the total FFM [31]. In adults, changes in lean tissue mass or FFM are generally due to changes in muscle mass, as the other components are known to be quite constant.

\section{Methods of Measuring Muscle Mass}

\section{Imaging Methods}

\section{Magnetic Resonance Imaging}

MRI has replaced the computed tomography (CT) scan as the gold standard [32]. MRI creates images from emission of radiofrequency energy from the nuclei of hydrogen atoms generated by magnetic fields and the signal will differ depending on the type of tissue [32]. MRI protocols can be optimized to assess the contrast among muscle tissue and fat tissue [33]. It also allows for quantification of FFM components, e.g., skeletal muscle mass, specific organ mass and bone marrow adipose tissue [14, 32]. MRI can also separate the muscle tissue into two different components, muscle with intramuscular fat and fat-free muscle. New methods to separate extracellular and intracellular muscle compartments can be used to show the expansion of extracellular space in aging and development of sarcopenia [34]. MRI is the most valuable tool for clinical research studies, due to the ability to quantify body compartments, which cannot be measured by other techniques. Furthermore, it can be used to assess relatively small changes over time which is useful in both intervention and observational studies [15]. Additionally, MRI can be used for body composition profiling, which is mainly used to compartmentalize the fat tissue but also to assess the weight muscle ratio [35]. General limitations of MRI are the costs, need for technicians, space requirements and infeasibility for patients with claustrophobia or with MRI incompatible implanted devices (e.g., cardiac pacemaker) [14]. The main drawbacks in a population with class II/III obesity are weight limitation (approx. $200 \mathrm{~kg}$ ) and radial size limit (approx. $60 \mathrm{~cm}$ ) [36]. MRI has been validated in healthy populations by post mortem cadaver studies in which subjects with obesity were also included, but with a maximum body mass index (BMI) of $31 \mathrm{~kg} / \mathrm{m}^{2}(r=0.97$; Table 2). The results of test-retest and inter-observer reliability were highly correlated (respectively: $2.9 \%, r=0.99$ and $2.6 \%$, $r=0.99$ ) [33, 38]. There are MRI machines available with open configuration, eliminating the radial size limitations, and with higher maximal weight (approx. $290 \mathrm{~kg}$ ) [39]. With these MRI machines, it might be possible to validate measurements of muscle mass in patients with morbid obesity. Finally, MRI can measure a single abdominal cross-sectional slice at the third lumbar vertebra (L3) level, which has been validated in individuals with obesity against total MRI imaging of the abdomen 


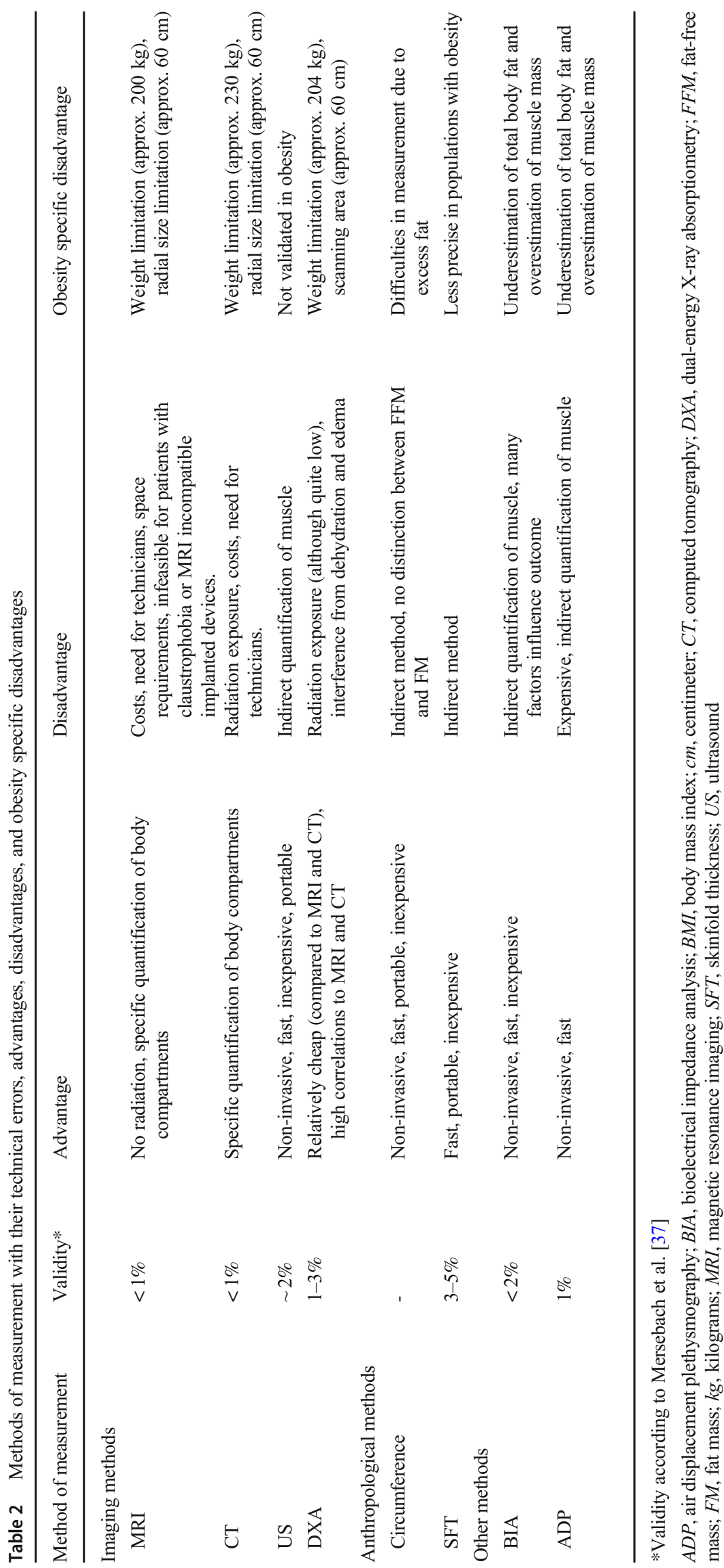


and allows for estimation of both visceral adiposity and skeletal muscle mass [19].

\section{Computed Tomography Scan}

In 1971, the CT scan was the first clinically accepted body composition measurement tool and was used as a gold standard [34]. The CT scan uses an X-ray beam to make crosssectional images of the body, which can estimate total body fat, visceral fat and skeletal muscle mass [40, 41]. A single cross-sectional image of the abdominal area at the level of the L3 has shown a high correlation with total body skeletal muscle mass and body adipose tissue, comparable to whole-body MRI results [42]. However, these studies have mainly been done in healthy populations and populations prone to wasting and thus might not be applicable in patients with obesity [43]. General limitations of CT are the costs, need for technicians and radiation exposure [14]. Obesity-related limitations are similar to MRI, as CT also has a weight limit (approx. $230 \mathrm{~kg}$ ) and radial size limit (approx. $60 \mathrm{~cm}$ ) [15]. The CT validity was also tested with cadaver dissection in non-obese individuals ( $r=0.97$; Table 2) [33]. The test-retest reliability showed a high correlation $(1.4 \%, r=0.999)$ [33, 44]. Currently, CT is rarely used to measure muscle mass.

\section{Dual-Energy X-ray Absorptiometry}

DXA is the best alternative to the gold standard. Originally invented to assess bone mineral content, DXA is now frequently used to examine body composition and muscle mass. It uses two X-ray beams to separate fat, bone and lean tissue based on the tissue X-ray absorption [45]. DXA highly correlates to both MRI and CT measures of skeletal muscle mass $[22,46,47]$. The main limitation is that muscle is not quantified directly. Several assumptions are made to calculate the lean soft tissue mass or FFM, based on the different gray-tones in the DXA scan. There can also be interference from both dehydration and edema, which are not unusual in populations with obesity $[48,49]$. The validity of the muscle measurements of the DXA compared to CT has been examined in non-obese volunteers ( $r=0.96$; Table 2$)$ [50]. The test-retest reliability between measures of FFM, also showed a high correlation $(r=0.99)$ [47]. However, these studies excluded individuals who did not fit within the DXA field-of-view or exceeded the CT radial size [50]. A recent study has shown that half-body analysis is comparable to the whole-body analysis for FM, non-bone lean mass and fat percentage. This halfbody analysis uses a symmetry assumption, in which the left part of the body should have the same fat and muscle distribution as the right part of the body. It can be used if patients do not fit in the DXA field-of-view [51, 52]. In short, the DXA can accurately predict the FFM, in both healthy individuals and individuals with obesity.

\section{Ultrasonography}

In ultrasonography (US), high-frequency sound waves travel through the skin and are reflected by the underlying tissues. The reflection is called the acoustic impedance and each tissue type has a unique impedance. The reflection, received by the transducer, is converted into electrical signals and then visualized on monitor [53]. The ultrasound is a non-invasive, fast and inexpensive tool $[53,54]$. Alterations in the muscle mass can also be measured with US [55]. The ultrasound is portable and therefore especially useful in critically ill patients at bedside [53]. There have been studies in healthy and older adults validating US in quantifying body composition, e.g., FM, especially visceral fat, and skeletal muscle thickness [55-57]. FM measurements with US have been validated with DXA in non-obese individuals ( $r=0.98$; Table 2) [58]. Estimation of lean tissue mass with US has not been validated in populations with obesity. The most commonly used sonographic devices have a maximum measuring depth of approximately $12 \mathrm{~cm}$ [59]. This limits the use in persons with morbid obesity, in whom subcutaneous fat thickness of more than $12 \mathrm{~cm}$ is not uncommon. Using an ultrasound with a lower frequency can solve this problem, as the penetration increases, however this will decrease the resolution of the image [60]. Future research on US to measure lean tissue in populations with obesity is underway. Finally, it might also be possible to look at muscle quality, which has already been validated in healthy athletes and critically ill patients $[61,62]$.

\section{Summary of Imaging Methods of Measuring Muscle Mass in Obesity}

MRI and CT have been the gold standard in measuring muscle mass for years. Both have a weight and radial size limit. Newer models have bigger radial size limits and there is even an open configuration MRI [34]. However, both MRI and CT are expensive and require trained personnel. Currently, the CT is rarely used for measuring muscle mass.

The DXA results (lean tissue mass and FFM) highly correlate with both $\mathrm{MRI}$ and $\mathrm{CT}$ measures of muscle mass and DXA is relatively cheap compared to MRI or CT [63]. DXA also has some limitations, e.g., need for trained personnel and (low levels of) radiation. DXA is already established and frequently used as an alternative to MRI to measure muscle mass. US to measure muscle is quite new and has not been tested in populations with obesity yet.

\section{Bioelectrical Impedance Analysis}

Bioelectrical impedance analysis (BIA) measures the electrical impedance (or flow) of an electric current through the body. Due to differences in electrical conductance, the total body water, FFM and body fat can be estimated [48]. The 
FFM is estimated based on a constant hydration of FFM of $73 \%$. The hydration of the FFM is higher in obesity (approx. $77.5 \%$ ) [48, 64]. Consequently, most prediction equations give an underestimation of the FM and an overestimation of the FFM when used in participants with obesity [65]. BIA has been validated against MRI in healthy subjects, but has not been done in a population with obesity $(r=0.87$; Table 2$)$ [66]. BIA is unreliable when compared to DXA results in a population with morbid obesity, overestimating the FFM with increasing errors as the BMI increases [21, 26, 27, 29, 48].

Furthermore, factors that can influence the outcome of the BIA measurement are food, alcohol, physical exercise, time of day, skin condition (perspiration), body shape, and some disease conditions or treatments [67].

\section{Air Displacement Plethysmography}

Air displacement plethysmography (ADP) is currently mostly performed in a BOD POD (Bod Pod Body Composition System, Concord, CA, USA), which calculates body volume. The difference in volume of the chamber, with versus without the patient, is the total body volume. The body volume can then be used to estimate the percentage of body fat $[68,69]$. The relative body fat is calculated using the following equation: percent fat $=495 /$ density $-450[68,70]$. Similar to the BIA, the ADP uses assumptions for calculating the FFM. This can give an underestimation of the FM and an overestimation of the FFM in persons with obesity [14]. ADP has been compared to hydrostatic weighing for its validity in measuring percentage body fat ( $r=0.93$; Table 2) [68]. Hydrostatic weighing also uses total body volume together with the same assumptions to calculate FM and FFM [71]. A validation study with ADP against DXA showed an overestimation of body fat in participants with a lower BMI and an underestimation of body fat in participants with a high BMI [72].

\section{Anthropometric Methods}

\section{Circumference and Skinfold Thickness}

Circumference measurements are done with a flexible quilting tape, making the measurements safe, easy and at low-cost [73]. The accuracy of circumference measurements depends on the skills and training of the person taking the measurements and can differ between observers [74]. Arm, thigh, and calf circumference together with skinfold thickness (SFT) can be used to estimate skeletal muscle mass. A prediction equation was developed to estimate the skeletal muscle mass: skeletal muscle mass $=$ height $\times\left[0.00744 \times\right.$ corrected arm girth ${ }^{2}+0.00088 \times$ corrected thigh girth $^{2}+0.0041 \times$ corrected calf girth $\left.{ }^{2}\right]+2.4 \times$ sex $-0.048 \times$ age + race $\times 7.8$. The correction of the circumferences is done by subtracting $\pi \times$ SFT from the measured circumference [75]. The equation was validated with MRI in patients with class I and II obesity [76].

\section{Biochemical Measurements}

\section{Creatinine}

Creatinine is a breakdown product of creatinine phosphate and is released from muscle cells with a usually fairly constant rate in to the blood. The classic method for the estimation of total skeletal muscle mass is 24-h urinary creatinine excretion, with the equation of $17-20 \mathrm{~kg}$ of muscle mass per gram of creatinine [77, 78]. This equation has been validated in patients with advanced renal failure, children, adolescents, elderly people and patients with wasting conditions, but not in populations with obesity [78-80]. One study also highlighted the relatively high day-today variability of creatinine excretion (approx. 4-8\%) and some influential factors on the secretion of creatinine (e.g., diet, exercise, menstrual cycle). It shows a high validity compared to anthropometric methods [78]. Serum creatinine can estimate muscle mass when serum cystatin $C$ is added to the equation. ${ }^{50}$ The equation has been developed and validated in a diverse population, only excluding patients with chronic kidney disease ( $r=$ 0.93) [81]. However, it has not been specifically validated in populations with obesity. Another relatively new tool is the $\mathrm{D}_{3^{-}}$ creatine dilution method. This method measures $\mathrm{D}_{3}$-creatine and $\mathrm{D}_{3}$-creatinine excretion in morning urine [82]. Creatine is needed for energy supply in the muscle and approximately $2 \%$ is converted into creatinine and excreted. With the $\mathrm{D}_{3}$-creatine method, subjects will ingest a single dose of stable isotope-labeled $\mathrm{D}_{3^{-}}$ creatine. $\mathrm{D}_{3}$-creatine will be taken up into muscle tissue and the excreted $\mathrm{D}_{3}$-creatinine will give an estimation of skeletal muscle creatine enrichment and thus total body creatine and total muscular mass [82-84]. There is less variability compared to 24-h urinary creatinine excretion and less dependence on subject compliance [83]. This specific method of measuring $\mathrm{D}_{3}$-creatine has yet to be validated in a population with obesity.

\section{Muscle Strength}

\section{Isokinetic Testing}

Isokinetic testing is the gold standard method to measure muscle strength. There are two main methods to measure isokinetic strength. The first method is the peak torque, which is the maximum amount of force that can be used to extend or flex the muscles around the knee $[85,86]$. Both strength and speed can be controlled during the measurement, leading to a more detailed assessment [87]. Studies in healthy men and elderly populations have found a correlation between isokinetic torque values and muscle mass and total muscle strength [88-90]. The second method is the one repetition maximum, in which the maximum 
weight that can be pushed once is measured [86]. It is usually measured with extension measures with a weight and pulley system. This method is less appropriate for vulnerable groups (e.g., elderly, cardiac and hypertensive patients), due to the chance of over bearing [91]. Neither one of these two methods has been studied in patients with obesity.

\section{Grip Strength}

A simple method to evaluate muscle strength is the hand-dynamometer, which measures the grip strength. Compared to isokinetic testing, the grip strength has shown to be a good alternative for measuring muscle strength [92]. It is associated with total body strength and total body muscle mass [93, 94]. Studies in assisted-living and community-dwelling older adults have shown that grip strength is associated with muscle mass and can help predict the FFM index (kg FFM/length) [5, 6]. These studies have only been performed in sarcopenia prone populations, without including individuals with obesity. Studies in populations with obesity mostly look at the measurement of physical fitness and are not related to muscle mass [95].

\section{Discussion}

MRI has replaced the CT scan as the gold standard for measurement of body composition, and the DXA scan is a good alternative. Limitations of these measurements are not uncommon when evaluating muscle mass in obesity. Most limitations regard to weight per se or difference in body composition compared to non-obese subjects and dealing with these limitations should be part of methodology. Unless the weight threshold is identified prior to the patient attending, there is potential for people with obesity to face a stigmatized situation in a routine clinical encounter. This needs to be avoided, with a clear need to make these diagnostic procedures more accessible to people with obesity. Furthermore, only a few methods have been validated in populations with obesity, especially in the higher classes of obesity. Further research should look at different methods to measure muscle mass in obesity, to find cheaper methods with less limitations regarding weight and size which can be made widely available for clinical practice.

\section{Compliance with Ethical Standards}

Conflict of Interest The authors declare that they have no conflict of interest.

Ethical Approval Statement This article does not contain any studies with human participants or animals performed by any of the authors.

Informed Consent Statement Informed Consent Statement does not apply.
Open Access This article is licensed under a Creative Commons Attribution 4.0 International License, which permits use, sharing, adaptation, distribution and reproduction in any medium or format, as long as you give appropriate credit to the original author(s) and the source, provide a link to the Creative Commons licence, and indicate if changes were made. The images or other third party material in this article are included in the article's Creative Commons licence, unless indicated otherwise in a credit line to the material. If material is not included in the article's Creative Commons licence and your intended use is not permitted by statutory regulation or exceeds the permitted use, you will need to obtain permission directly from the copyright holder. To view a copy of this licence, visit http://creativecommons.org/licenses/by/4.0/.

\section{References}

1. Benaiges D, Goday A, Pedro-Botet J, et al. Bariatric surgery: to whom and when? Minerva Endocrinol. 2015;40:119-28.

2. Buchwald H, Avidor Y, Braunwald E, et al. Bariatric surgery: a systematic review and meta-analysis. JAMA. 2004;292:1724-37.

3. Coutinho T, Goel K, Corrêa de Sá D, et al. Central obesity and survival in subjects with coronary artery disease: a systematic review of the literature and collaborative analysis with individual subject data. J Am Coll Cardiol. 2011;57:1877-86.

4. Bray GA, Jablonski KA, Fujimoto WY, et al. Relation of central adiposity and body mass index to the development of diabetes in the Diabetes Prevention Program. Am J Clin Nutr. 2008;87:1212-8.

5. McIntosh EI, Smale KB, Vallis LA. Predicting fat-free mass index and sarcopenia: a pilot study in community-dwelling older adults. Age Dordr Neth. 2013;35:2423-34.

6. Campbell TM, Vallis LA. Predicting fat-free mass index and sarcopenia in assisted-living older adults. Age Dordr Neth. 2014;36:9674.

7. Cho Y, Shin S-Y, Shin M-J. Sarcopenic obesity is associated with lower indicators of psychological health and quality of life in Koreans. Nutr Res N Y N. 2015;35:384-92.

8. Tian S, Xu Y. Association of sarcopenic obesity with the risk of allcause mortality: a meta-analysis of prospective cohort studies. Geriatr Gerontol Int. 2016;16:155-66.

9. Kreidieh D, Itani L, El Masri D, et al. Association between sarcopenic obesity, type 2 diabetes, and hypertension in overweight and obese treatment-seeking adult women. J Cardiovasc Dev Dis. 2018;5

10. Maïmoun L, Lefebvre P, Aouinti S, et al. Acute and longer-term body composition changes after bariatric surgery. Surg Obes Relat Dis Off J Am Soc Bariatr Surg. 2019;15:1965-73.

11. Plush C, Johnson C, Singh A, et al. Comment on: Acute and longerterm body composition changes after bariatric surgery. Surg Obes Relat Dis Off J Am Soc Bariatr Surg. 2019;15:1974-6.

12. Sivakumar J, Chong L, Ward S, et al. Body composition changes following a very-low-calorie pre-operative diet in patients undergoing bariatric surgery. Obes Surg. 2020;30:119-26.

13. Baumgartner RN. Body composition in healthy aging. Ann N Y Acad Sci. 2000;904:437-48.

14. Lemos T, Gallagher D. Current body composition measurement techniques. Curr Opin Endocrinol Diabetes Obes. 2017;24:310-4.

15. Andreoli A, Garaci F, Cafarelli FP, et al. Body composition in clinical practice. Eur J Radiol. 2016;85:1461-8.

16. Chen L, Nelson DR, Zhao Y, et al. Relationship between muscle mass and muscle strength, and the impact of comorbidities: a population-based, cross-sectional study of older adults in the United States. BMC Geriatr. 2013;13:74.

17. Uritani D, Matsumoto D, Asano Y, et al. Effects of regular exercise and nutritional guidance on body composition, blood pressure, 
muscle strength and health-related quality of life in communitydwelling Japanese women. Obes Res Clin Pract. 2013;7:e155-63.

18. Marques LP, Confortin SC, Ono LM, et al. Quality of life associated with handgrip strength and sarcopenia: EpiFloripa Aging Study. Arch Gerontol Geriatr. 2019;81:234-9.

19. Baker ST, Strauss BJ, Prendergast LA, et al. Estimating dualenergy X-ray absorptiometry-derived total body skeletal muscle mass using single-slice abdominal magnetic resonance imaging in obese subjects with and without diabetes: a pilot study. Eur J Clin Nutr. 2012;66:628-32.

20. Blue MNM, Hirsch KR, Trexler ET, et al. Validity of the 4compartment model using dual energy X-ray absorptiometry-derived body volume in overweight individuals. Appl Physiol Nutr Metab Physiol Appl Nutr Metab. 2018;43:742-6.

21. Boneva-Asiova Z, Boyanov MA. Body composition analysis by leg-to-leg bioelectrical impedance and dual-energy X-ray absorptiometry in non-obese and obese individuals. Diabetes Obes Metab. 2008;10:1012-8.

22. Bredella MA, Ghomi RH, Thomas BJ, et al. Comparison of DXA and $\mathrm{CT}$ in the assessment of body composition in premenopausal women with obesity and anorexia nervosa. Obes Silver Spring Md. 2010;18:2227-33.

23. Bucaloiu ID, Wood GC, Norfolk ER, et al. Fat-free weight prediction in morbidly obese females. Int J Nephrol Renov Dis. 2011;4:149-55.

24. Jebb SA, Siervo M, Murgatroyd PR, et al. Validity of the leg-to-leg bioimpedance to estimate changes in body fat during weight loss and regain in overweight women: a comparison with multicompartment models. Int J Obes 2005. 2007;31:756-62.

25. Levitt DG, Beckman LM, Mager JR, et al. Comparison of DXA and water measurements of body fat following gastric bypass surgery and a physiological model of body water, fat, and muscle composition. J Appl Physiol Bethesda Md 1985. 2010;109:786-95.

26. Savastano S, Belfiore A, Di Somma C, et al. Validity of bioelectrical impedance analysis to estimate body composition changes after bariatric surgery in premenopausal morbidly women. Obes Surg. 2010;20:332-9.

27. Shafer KJ, Siders WA, Johnson LK, et al. Validity of segmental multiple-frequency bioelectrical impedance analysis to estimate body composition of adults across a range of body mass indexes. Nutr Burbank Los Angel Cty Calif. 2009;25:25-32.

28. Silver HJ, Niswender KD, Kullberg J, et al. Comparison of gross body fat-water magnetic resonance imaging at 3 Tesla to dualenergy X-ray absorptiometry in obese women. Obes Silver Spring Md. 2013;21:765-74.

29. Ward LC, Dyer JM, Byrne NM, et al. Validation of a threefrequency bioimpedance spectroscopic method for body composition analysis. Nutr Burbank Los Angel Cty Calif. 2007;23:657-64.

30. Heymsfield SB, Gonzalez MC, Lu J, et al. Skeletal muscle mass and quality: evolution of modern measurement concepts in the context of sarcopenia. Proc Nutr Soc. 2015;74:355-66.

31. Scafoglieri A, Clarys JP. Dual energy X-ray absorptiometry: gold standard for muscle mass? J Cachexia Sarcopenia Muscle. 2018;9:786-7.

32. Erlandson MC, Lorbergs AL, Mathur S, et al. Muscle analysis using pQCT, DXA and MRI. Eur J Radiol. 2016;85:1505-11.

33. Mitsiopoulos N, Baumgartner RN, Heymsfield SB, et al. Cadaver validation of skeletal muscle measurement by magnetic resonance imaging and computerized tomography. J Appl Physiol Bethesda Md 1985. 1998;85:115-22.

34. Heymsfield SB, Adamek M, Gonzalez MC, et al. Assessing skeletal muscle mass: historical overview and state of the art. J Cachexia Sarcopenia Muscle. 2014;5:9-18.

35. Linge J, Borga M, West J, et al. Body composition profiling in the UK Biobank Imaging Study. Obes Silver Spring Md. 2018;26:1785-95.

36. Hedderich DM, Hasenberg T, Haneder S, et al. Effects of bariatric surgery on non-alcoholic fatty liver disease: magnetic resonance imaging is an effective, non-invasive method to evaluate changes in the liver fat fraction. Obes Surg. 2017;27:1755-62.

37. Mersebach H, Feldt-Rasmussen U. Growth hormone and body composition. Front Horm Res. 2005;33:185-95.

38. Abate N, Burns D, Peshock RM, et al. Estimation of adipose tissue mass by magnetic resonance imaging: validation against dissection in human cadavers. J Lipid Res. 1994;35:1490-6.

39. Martin RCG. Intraoperative magnetic resonance imaging ablation of hepatic tumors. Am J Surg. 2005;189:388-94.

40. Gibson DJ, Burden ST, Strauss BJ, et al. The role of computed tomography in evaluating body composition and the influence of reduced muscle mass on clinical outcome in abdominal malignancy: a systematic review. Eur J Clin Nutr. 2015;69:1079-86.

41. Binay Safer V, Safer U. Usefulness and limitations of single-slice computed tomography analysis at the third lumbar region in the assessment of sarcopenia. Crit Care. 2013;17:466.

42. Shen W, Punyanitya M, Wang Z, et al. Total body skeletal muscle and adipose tissue volumes: estimation from a single abdominal cross-sectional image. J Appl Physiol Bethesda Md 1985. 2004;97:2333-8.

43. Lacoste Jeanson A, Dupej J, Villa C, Brůžek J. Body composition estimation from selected slices: equations computed from a new semi-automatic thresholding method developed on whole-body CT scans. PeerJ. 2017 [cited 2018 Dec 19];5. Available from: https://www.ncbi.nlm.nih.gov/pmc/articles/PMC5438582/.

44. Hudash G, Albright JP, McAuley E, et al. Cross-sectional thigh components: computerized tomographic assessment. Med Sci Sports Exerc. 1985;17:417-21.

45. Pietrobelli A, Formica C, Wang Z, et al. Dual-energy X-ray absorptiometry body composition model: review of physical concepts. Am J Phys. 1996;271:E941-51.

46. Geisler C, Pourhassan M, Braun W, et al. The prediction of total skeletal muscle mass in a Caucasian population - comparison of magnetic resonance imaging (MRI) and dual-energy X-ray absorptiometry (DXA). Clin Physiol Funct Imaging. 2017;37:168-72.

47. Levine JA, Abboud L, Barry M, et al. Measuring leg muscle and fat mass in humans: comparison of $\mathrm{CT}$ and dual-energy X-ray absorptiometry. J Appl Physiol Bethesda Md 1985. 2000;88:452-6.

48. Johnson Stoklossa CA, Forhan M, Padwal RS, et al. Practical considerations for body composition assessment of adults with class II/ III obesity using bioelectrical impedance analysis or dual-energy Xray absorptiometry. Curr Obes Rep. 2016;5:389-96.

49. Toombs RJ, Ducher G, Shepherd JA, et al. The impact of recent technological advances on the trueness and precision of DXA to assess body composition. Obes Silver Spring Md. 2012;20:30-9.

50. Taylor AE, Kuper H, Varma RD, Wells JC, Bell JD, Radhakrishna VK, et al. Validation of dual energy X-ray Absorptiometry measures of abdominal fat by comparison with magnetic resonance imaging in an Indian population. PLoS One. 2012 [cited 2019 Jan 2];7. Available from: https://www.ncbi.nlm.nih.gov/pmc/ articles/PMC3522679/.

51. Rothney MP, Brychta RJ, Schaefer EV, et al. Body composition measured by dual-energy X-ray absorptiometry half-body scans in obese adults. Obes Silver Spring Md. 2009;17:1281-6.

52. Kim J, Heshka S, Gallagher D, et al. Intermuscular adipose tissue-free skeletal muscle mass: estimation by dual-energy X-ray absorptiometry in adults. J Appl Physiol Bethesda Md 1985. 2004;97:655-60.

53. Mourtzakis M, Wischmeyer P. Bedside ultrasound measurement of skeletal muscle. Curr Opin Clin Nutr Metab Care. 2014;17:389-95.

54. Toledo DO, de LE Silva DC, Santos DMD, et al. Bedside ultrasound is a practical measurement tool for assessing muscle mass. Rev Bras Ter Intensiva. 2017;29:476-80.

55. Bazzocchi A, Filonzi G, Ponti F, et al. Ultrasound: which role in body composition? Eur J Radiol. 2016;85:1469-80.

56. Arts IMP, Pillen S, Schelhaas HJ, et al. Normal values for quantitative muscle ultrasonography in adults. Muscle Nerve. 2010;41:32-41. 
57. Ticinesi A, Meschi T, Narici MV, et al. Muscle ultrasound and sarcopenia in older individuals: a clinical perspective. J Am Med Dir Assoc. 2017;18:290-300.

58. Pineau J-C, Guihard-Costa A-M, Bocquet M. Validation of ultrasound techniques applied to body fat measurement. A comparison between ultrasound techniques, air displacement plethysmography and bioelectrical impedance vs. dual-energy X-ray absorptiometry. Ann Nutr Metab. 2007;51:421-7.

59. Philips Lumify L12-4 Linear Array Transducer | Philips Healthcare. Philips. [cited 2019 Mar 28]. Available from: https://www.philips. nl/healthcare/product/HC989605451352/lumify-112-4-transducerbroadband-linear-array-transducer.

60. Wagner DR. Ultrasound as a tool to assess body fat. J Obes. 2013 [cited 2018 Dec 19];2013. Available from: https://www.ncbi.nlm. nih.gov/pmc/articles/PMC3770049/.

61. Hill JC, Millán IS. Validation of musculoskeletal ultrasound to assess and quantify muscle glycogen content. A novel approach. Phys Sportsmed. 2014;42:45-52.

62. Looijaard WGPM, Dekker IM, Stapel SN, Girbes ARJ, Twisk JWR, Oudemans-van Straaten HM, et al. Skeletal muscle quality as assessed by CT-derived skeletal muscle density is associated with 6-month mortality in mechanically ventilated critically ill patients. Crit Care. 2016 [cited 2019 Jan 30];20. Available from: http:// ccforum.biomedcentral.com/articles/10.1186/s13054-016-1563-3.

63. Kim J, Wang Z, Heymsfield SB, et al. Total-body skeletal muscle mass: estimation by a new dual-energy X-ray absorptiometry method. Am J Clin Nutr. 2002;76:378-83.

64. Franco-Villoria M, Wright $\mathrm{CM}, \mathrm{McColl} \mathrm{JH}$, et al. Assessment of adult body composition using bioelectrical impedance: comparison of researcher calculated to machine outputted values. BMJ Open. 2016;6:e008922.

65. Coppini LZ, Waitzberg DL, Campos ACL. Limitations and validation of bioelectrical impedance analysis in morbidly obese patients. Curr Opin Clin Nutr Metab Care. 2005;8:329-32.

66. Forde C. Comparison of bioelectrical impedance analysis and magnetic resonance imaging for the quantification of fat mass. Int $\mathrm{J}$ Physiatry. 2015 [cited 2018 Dec 20];1. Available from: https:// clinmedjournals.org/articles/ijp/international-journal-of-physiatryijp-1-003.php?jid=ijp.

67. Kyle UG, Bosaeus I, De Lorenzo AD, et al. Bioelectrical impedance analysis-part II: utilization in clinical practice. Clin Nutr Edinb Scotl. 2004;23:1430-53.

68. Mccrory MA, Gomez TD, Bernauer EM, et al. Evaluation of a new air displacement plethysmograph for measuring human body composition. Med Sci Sports Exerc. 1995;27:1686-91.

69. Dempster P, Aitkens S. A new air displacement method for the determination of human body composition. Med Sci Sports Exerc. 1995;27:1692-7.

70. Siri WE. Body composition from fluid spaces and density: analysis of methods. 1961. Nutr Burbank Los Angel Cty Calif. 1993;9:480 91. discussion 480, 492.

71. Ginde SR, Geliebter A, Rubiano F, et al. Air displacement plethysmography: validation in overweight and obese subjects. Obes Res. 2005;13:1232-7.

72. Lowry DW, Tomiyama AJ. Air displacement plethysmography versus dual-energy x-ray absorptiometry in underweight, normal-weight, and overweight/obese individuals. PLoS One. 2015;10:e0115086.

73. Teran JC, Sparks KE, Quinn LM, et al. Percent body fat in obese white females predicted by anthropometric measurements. Am J Clin Nutr. 1991;53:7-13.

74. Wang J, Gallagher D, Thornton JC, et al. Regional body volumes, BMI, waist circumference, and percentage fat in severely obese adults. Obes Silver Spring Md. 2007;15:2688-98.

75. Lohman T, Roche A, Martorell R. Anthropometric standardization reference manual. Champaign: Human Kinetics; 1988.
76. Lee RC, Wang Z, Heo M, et al. Total-body skeletal muscle mass: development and cross-validation of anthropometric prediction models. Am J Clin Nutr. 2000;72:796-803.

77. Proctor DN, O'Brien PC, Atkinson EJ, et al. Comparison of techniques to estimate total body skeletal muscle mass in people of different age groups. Am J Physiol-Endocrinol Metab. 1999;277:E489-95.

78. Heymsfield SB, Arteaga C, McManus C, et al. Measurement of muscle mass in humans: validity of the 24-hour urinary creatinine method. Am J Clin Nutr. 1983;37:478-94.

79. Jassal SK, Wassel CL, Laughlin GA, et al. Urine creatinine-based estimates of fat-free mass in community-dwelling older persons: the Rancho Bernardo study. J Ren Nutr Off J Counc Ren Nutr Natl Kidney Found. 2015;25:97-102.

80. Polinder-Bos HA, Nacak H, Dekker FW, et al. Low urinary creatinine excretion is associated with self-reported frailty in patients with advanced chronic kidney disease. Kidney Int Rep. 2017;2:676-85.

81. Kim S, Jung H-W, Kim C-H, et al. A new equation to estimate muscle mass from creatinine and cystatin C. PLoS One. 2016;11:e0148495.

82. Clark RV, Walker AC, Miller RR, et al. Creatine (methyl-d3) dilution in urine for estimation of total body skeletal muscle mass: accuracy and variability vs. MRI and DXA. J Appl Physiol. 2017;124:1-9.

83. Clark RV, Walker AC, O'Connor-Semmes RL, et al. Total body skeletal muscle mass: estimation by creatine (methyl-d3) dilution in humans. J Appl Physiol Bethesda Md 1985. 2014;116:1605-13.

84. Shankaran M, Czerwieniec G, Fessler C, et al. Dilution of oral D3creatine to measure creatine pool size and estimate skeletal muscle mass: development of a correction algorithm. J Cachexia Sarcopenia Muscle. 2018;9:540-6.

85. Gleeson NP, Mercer TH. The utility of isokinetic dynamometry in the assessment of human muscle function. Sports Med Auckl NZ. 1996;21:18-34.

86. American College Of Sports Medicine. ACSM's guidelines for exercise testing and prescription. 10th ed: Lippincott Williams And Wilkins; 2017.

87. Adams G. Exercise Physiology Laboratory Manual. Europe: McGraw-Hill Education; 2013.

88. Knapik JJ, Wright JE, Mawdsley RH, et al. Isokinetic, isometric and isotonic strength relationships. Arch Phys Med Rehabil. 1983;64:77-80.

89. Abernethy PJ, Jürimäe J. Cross-sectional and longitudinal uses of isoinertial, isometric, and isokinetic dynamometry. Med Sci Sports Exerc. 1996;28:1180-7.

90. Reed RL, Pearlmutter L, Yochum K, et al. The relationship between muscle mass and muscle strength in the elderly. J Am Geriatr Soc. 1991;39:555-61.

91. Gaines JM, Talbot LA. Isokinetic strength testing in research and practice. Biol Res Nurs. 1999;1:57-64.

92. Stark T, Walker B, Phillips JK, et al. Hand-held dynamometry correlation with the gold standard isokinetic dynamometry: a systematic review. PM R. 2011;3:472-9.

93. Bohannon RW. Muscle strength: clinical and prognostic value of hand-grip dynamometry. Curr Opin Clin Nutr Metab Care. 2015;18:465-70.

94. Omichi Y, Srivareerat M, Panorchan K, et al. Measurement of muscle strength in haemodialysis patients by pinch and hand grip strength and comparison to lean body mass measured by multifrequency bioelectrical impedance. Ann Nutr Metab. 2016;68:268-75.

95. Otto M, Kautt S, Kremer M, et al. Handgrip strength as a predictor for post bariatric body composition. Obes Surg. 2014;24:2082-8.

Publisher's Note Springer Nature remains neutral with regard to jurisdictional claims in published maps and institutional affiliations. 